\title{
Hospital morbidity among elderly in the region of Sfax, Tunisia: Epidemiological profile and chronological trends between 2003 and 2015
}

\author{
Yaïch Sourour $^{\mathrm{a}}$, Ben Ayed Houda ${ }^{\mathrm{a}, *}$, Trigui Maroua ${ }^{\mathrm{b}}$, Ben Hmida Mariemª ${ }^{\mathrm{a}}$, Ben Jmaa Maïssa ${ }^{\mathrm{a}}$, \\ Mejdoub Yosra ${ }^{\mathrm{a}}$, Jedidi Jihene ${ }^{\mathrm{a}}$, Feki Habib ${ }^{\mathrm{b}}$, Karray Raouf ${ }^{\mathrm{a}}$, Damak Jamel ${ }^{\mathrm{a}}$

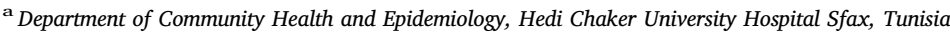 \\ ${ }^{\mathrm{b}}$ Department of Preventive Medicine and Hygiene, Tunisia
}

\section{Introduction}

Nowadays, populations ageing has become a challenging universal phenomenon. According to the WHO, between 2015 and 2050, the proportion of the world population over 60 years would nearly double from $12 \%$ to $22 \% .^{1}$ In $2050,80 \%$ of older people would be living in low and middle-income countries. ${ }^{1}$ According to the census of population in 2014; this age group represented $11.38 \%$ in Tunisia. $^{2}$ Besides, this phenomenon seems to be accelerated in our country: the projections of the national institute of statistics estimated that one person in five would be aged more than 60 years in $2039 .{ }^{3}$ Ageing occurs most often in parallel with an increase of chronic and degenerative diseases, which resulted in a serious degradation of health. ${ }^{4}$ Facing the needs of care generated by these health problems, the answers depend on the medical skills and knowledge, the network of care and socio-economical context. These needs remain unrecognized in Tunisia, because of the lack of studies achieved around this period of life. ${ }^{5}$ However, the present demographic trends and the structural change of morbidity in elderly, added to their impact on the health needs must be imperatively processed at the time of the health planning in each country.

In this perspective, our study aimed to describe the epidemiological profile of hospital morbidity and mortality among elderly patients in our region over a 13-year period and to highlight the current trends, changes and issues affecting them.

\section{Methods}

\subsection{Study settings}

Hedi Chaker University Hospital is an 889-bed tertiary level teaching hospital in the region of Sfax, Tunisia. It includes 18 medical departments.

\subsection{Study design and data collection}

We conducted a retrospective exploratory study including all patients aged 60 years and above, native of Sfax and hospitalized at Hedi Chaker University Hospital from January 1st, 2003 to December 31st, 2015. During this period, hospitalization date was reliable and exhaustive. For practical reasons, Department of Internal Medicine, Neurology and Department of Medical Oncology were not included in our survey. We obtained data from the regional morbidity register of the University Hospital of Sfax. Then we checked collected data at the Department of Community Health and Epidemiology of Sfax (CHE) and entered them with "Epi-info" software. This register was implemented in the department of CHE since 1999 and received information periodically from all departments of the University Hospital of Sfax. The database variables included patient's socio-demographic characteristics, co-morbidities and length of hospital stay. We collected also exhaustive information dealing with the discharge status (home return, transfer to other departments or others hospitals, against medical advice and death). We used the tenth revision of International Classification of Diseases codes (ICD-10) to identify and classify morbid conditions. ${ }^{6}$

\subsection{Statistical analysis}

Statistical analysis was performed using SPSS.20 software. The Kolmogorov-Smirnov test was used to assess the distribution of quantitative variables. The results of quantitative variables were presented as means \pm standard deviation (SD) or medians and interquartile range (IQR). Those of qualitative variables were presented as numbers and percentages. We used the $\mathrm{T}$ test to compare two means and Anova test or Kruskal - Wallis test to compare several means. For categorical variables, we used the Chi-square test in independent samples. All rehospitalizations were excluded in order to take in consideration only the new cases, while calculating incidence. The in-hospital incidence rate and the in-hospital mortality rate were calculated based on Tunisian National Institute of Statistics data and were respectively expressed as the number per 1000 inhabitants (inh) and the number per 10.000 inhabitants (6). The average population was calculated as follows: (Sfax population in $2004+$ Sfax population in 2014)/2. ${ }^{2}$ In order to illustrate the trends of hospital morbidity we used tracer diseases:

\footnotetext{
* Corresponding author. Hedi Chaker University Hospital, Department of community Health and Epidemiology, Sfax, Tunisia. Tel.: + 21674106200.

E-mail address: drhoudabayed@gmail.com (B.A. Houda).
} 
Ischemic heart diseases (I20-I25), Diabetes mellitus (E10-E14), Renal failure (N17-N19), Malignant neoplasms (C00-C97), Chronic lower respiratory diseases (J40-J47) and Heart failure (I50). Diagnosis diseases were also classified into two groups: communicable and noncommunicable diseases. Communicable diseases were defined as diseases that can be transmitted and make people ill, caused by infectious agents, and which invade the body and multiply or release toxins. The hospitalizations for communicable diseases categories were those reported previously in the literature. ${ }^{7,8}$ The study of chronological trends was performed using Chi square for trends test (Chi-2; p) and linear regression analysis $(\beta, \mathrm{p})$. A p-value of $<0.05$ was considered statistically significant.

\section{Results}

\subsection{Admissions' characteristics}

During the 13-year study-period, we recorded 121985 hospitalizations in the University Hospital, among which 28281 cases were aged 60 years and above, which represented an annual hospitalization proportion in this age group equal to $23.18 \%$ of all hospitalizations. This proportion increased significantly over time $($ Rho $=0.72, \mathrm{p}=0.006)$. Among elderly, the in-hospital incidence was 22.5 admissions/1000 inhabitants/year. At enrollment, men were slightly more frequent than women (sex-ratio $=1.08$ ). The mean age was 70.65 years with a SD of 7.2 years. Age range 65-74 years was the most represented $(46.2 \%)$ in our study. We did not note any statistical difference in the mean age between men and women (70.67 years VS 70.62 years, $p=0.5$ ). Linear regression analysis showed that the mean age has significantly increased over time $(\beta=0.42, p<0.01)$. We noted a seasonal variation during the study period, with a peak of hospitalization in spring (31.1\%). The median hospital length of stay (LOS) was 8 days (IQR 4-13 days). It has been relatively risen in the departments of gastroenterology (13.01 days), pneumo-phtysiology (12.1 days) and psychiatry (10.5 days). Forty nine percent of patients were hospitalized less than a week. Home return was the most common discharge status (93.5\%) (Table 1).

\subsection{Morbidity and mortality}

Of all hospitalizations, major diagnostic categories among elderly were dominated by diseases of the circulatory system, diseases of the respiratory system, diseases of the genitourinary system, endocrine, nutritional and metabolic diseases as well as neoplasms. These morbid conditions represented $76.6 \%$ of all hospitalization patterns (Table 2).

The distribution of main ICD-10 chapters by gender revealed that the women's morbidity profile was dominated by the diseases of the genitourinary system, followed by endocrine, nutritional and metabolic diseases, then the diseases of the musculoskeletal system and connective tissue, whereas the circulatory system diseases, the respiratory system diseases and neoplasms were the most frequent pathologies in men.

A more detailed analysis of pathologies by gender showed that ischemic heart diseases (OR $=1.5$; CI95\% $=[1.5-1.7]$; $\mathrm{p}<0.01$ ), malignant neoplasms $(\mathrm{OR}=1.7 ; \mathrm{CI} 95 \%=[1.6-1.9] ; \mathrm{p}<0.01)$, and chronic lower respiratory diseases $(\mathrm{OR}=2.2 ; \mathrm{CI} 95 \%=[2-2.5]$; $\mathrm{p}<0.01$ ), were significantly more frequent in men, while diabetes mellitus (OR $=0.76 ; \quad \mathrm{CI} 95 \%=[0.70-0.80] ; \mathrm{p}<0.01)$, and renal failure $(\mathrm{OR}=0.8$; CI95\% $=[0.7-0.9] ; \mathrm{p}<0.01)$, were significantly more observed in women (Table 3). According to our findings, noncommunicable diseases represented $85.08 \%$ of all hospitalizations.

Among the total admissions, the in-hospital lethality rate was $1.1 \%$ over a 13-year period, with an in-hospital mortality rate of 2.4 deaths/ year/10.000 inhabitants.
Table 1

Hospitalizations characteristics in elderly between 2003 and 2015.

\begin{tabular}{|c|c|c|}
\hline Admissions characteristics & Number of admissions & $\%$ \\
\hline \multicolumn{3}{|l|}{ Age (years) } \\
\hline $60-64$ & 6849 & 24.2 \\
\hline $65-74$ & 13061 & 46.2 \\
\hline$\geq 75$ & 8371 & 29.6 \\
\hline \multicolumn{3}{|l|}{ Gender } \\
\hline Male & 14742 & 52.1 \\
\hline Female & 13539 & 47.9 \\
\hline \multicolumn{3}{|l|}{ Admission type } \\
\hline Direct & 26297 & 93 \\
\hline Transfer & 1984 & 7 \\
\hline \multicolumn{3}{|l|}{ Season } \\
\hline Winter & 6981 & 24.7 \\
\hline Spring & 8791 & 31.1 \\
\hline Summer & 7016 & 24.8 \\
\hline Autumn & 5493 & 19.4 \\
\hline \multicolumn{3}{|l|}{ Department } \\
\hline Cardiology & 10338 & 36.6 \\
\hline Pneumo-phtysiology & 4277 & 15.1 \\
\hline Endocrinology & 2965 & 10.5 \\
\hline Infectious diseases & 2872 & 10.2 \\
\hline Nephrology & 2270 & 8 \\
\hline Other departments & 5559 & 19.6 \\
\hline \multicolumn{3}{|l|}{ Length Of Stay } \\
\hline$\leq 7$ days & 13867 & 49 \\
\hline 8-14 days & 8455 & 29.9 \\
\hline$\geq 15$ days & 5959 & 21.1 \\
\hline \multicolumn{3}{|l|}{ Discharge status } \\
\hline Death & 306 & 1.1 \\
\hline Against medical advice & 692 & 2.4 \\
\hline Home return & 26438 & 93.5 \\
\hline Transfer & 865 & 3.1 \\
\hline
\end{tabular}

\subsection{Chronological trends of diseases}

The overall proportion of non-communicable diseases increased significantly from $79.3 \%$ in 2003 to $90.91 \%$ in 2015 (Rho $=0.61$, $\mathrm{p}=0.02)$; (Chi-2 $=46.9 ; \mathrm{p}<0.001$ ). In parallel, the proportion of communicable diseases decreased significantly from $20.7 \%$ to $9.09 \%$ in the same period (Rho $=-0.61, \mathrm{p}=0.02$ ) (Fig. 1).

The chronological trends of hospital morbidity showed that the tracer diseases had risen significantly, except chronic lower respiratory diseases, which remained stable. Over a 13-year period, the hospital incidence of ischemic heart diseases (Chi-2 = 39.1; $p<0.001$ ), as well as heart failure (Chi-2 $=103.5 ; \mathrm{p}<0.001$ ) had significantly increased from 2.8 cases/year $/ 10^{3} \mathrm{Inh}$. to 8.99 cases/year $/ 10^{3} \mathrm{Inh}$, and from 2.1 cases/year $/ 10^{3}$ Inh. to 5.3 cases/year $/ 10^{3}$ Inh, respectively. As to diabetes mellitus, we noted also a significant rise from 1.26 cases/year/ 1000 Inh. to 4.25 cases/year $/ 10^{3}$ Inh (Chi-2 $\left.=4.8 ; \mathrm{p}=0.04\right)$. Additionally, malignant neoplasms (Chi-2 $=29.1$; $p<0.001)$ had significantly risen from 0.98 cases/year $/ 10^{3} \mathrm{Inh}$. to 2.92 cases/year/ $10^{3}$ Inh (Fig. 2).

\section{Discussion}

The health status of aged people has been clearly improved during these last decades. ${ }^{9}$ However, the rise of life expectancy leaded to additional functional inabilities and chronic diseases. ${ }^{10}$ Indeed, elderly suffer from physical vulnerability related to the frailties and weaknesses. Therefore, they are frequently confronted to several health problems and then hospitalization would be necessary and unavoidable. In this perspective, it has been reported that hospitalization rates are increasing continually with age. ${ }^{9}$ In our survey, the annual hospitalization proportion was $23.18 \%$. This result was slightly more elevated than the rate found by Zedini and al. $(13.5 \%),{ }^{5}$ by Garcia $O$. and al. $(15.2 \%)^{11}$ and by Sanya $(11.1 \%){ }^{12}$ This could be explained by the fact that we have included the age group 60-64 years, as it was defined, 
Table 2

Distribution of main ICD-10 chapters by gender between 2003 and 2015 .

\begin{tabular}{|c|c|c|c|c|c|c|c|}
\hline \multirow[t]{2}{*}{ Main ICD-10 chapters } & \multirow[t]{2}{*}{ Codes } & \multicolumn{4}{|l|}{ Gender } & \multicolumn{2}{|l|}{ Total } \\
\hline & & $\mathrm{F}$ & $\%$ & M & $\%$ & Total & $\%$ \\
\hline IX-Diseases of the circulatory system & I00-I99 & 4356 & 32.2 & 5563 & 37.7 & 9919 & 35.1 \\
\hline $\mathrm{X}$ - Diseases of the respiratory system & J00-J99 & 1312 & 9.7 & 2148 & 14.6 & 3460 & 12.2 \\
\hline XIV- Diseases of the genitourinary system & N00-N99 & 2078 & 15.3 & 1240 & 8.4 & 3318 & 11.7 \\
\hline IV- Endocrine, nutritional and metabolic diseases & E00-E90 & 1721 & 12.7 & 1334 & 9 & 3055 & 10.8 \\
\hline II- Neoplasms & C00-D48 & 736 & 5.4 & 1197 & 8.1 & 1933 & 6.8 \\
\hline XVIII- Symptoms, signs and abnormal clinical and laboratory findings, not elsewhere classified & R00-R99 & 653 & 4.8 & 896 & 6.1 & 1549 & 5.5 \\
\hline XIII- Diseases of the musculoskeletal system and connective tissue & M00-M99 & 940 & 6.9 & 553 & 3.8 & 1493 & 5.3 \\
\hline I- Certain infectious and parasitic diseases & A00-B99 & 688 & 5.1 & 648 & 4.4 & 1336 & 4.7 \\
\hline XI- Diseases of the digestive system & К00-K93 & 539 & 4 & 653 & 4.4 & 1192 & 4.2 \\
\hline Others & - & 516 & 3.9 & 510 & 3.5 & 1026 & 3.7 \\
\hline TOTAL & & 13539 & 100 & 14742 & 100 & 28281 & 100 \\
\hline
\end{tabular}

ICD: International Classification of Diseases.

Table 3

Distribution of tracer diseases in elderly by gender between 2003 and 2015 .

\begin{tabular}{|c|c|c|c|c|c|c|}
\hline \multirow[t]{2}{*}{ Main Diagnoses } & \multicolumn{2}{|l|}{ Men } & \multicolumn{2}{|l|}{ Women } & \multirow{2}{*}{$\begin{array}{l}\text { OR } \\
-(\mathrm{CI} 95 \%)\end{array}$} & \multirow[t]{2}{*}{$\mathrm{p}$} \\
\hline & Number & $\%$ & Number & $\%$ & & \\
\hline $\begin{array}{l}\text { Ischemic heart diseases } \\
\quad(\underline{\mathrm{I} 20}-\underline{\mathrm{I} 25})\end{array}$ & 3695 & 25.1 & 2305 & 17 & $\begin{array}{l}1.6 \\
{[1.5-1.7]}\end{array}$ & $<0.01$ \\
\hline $\begin{array}{l}\text { Diabetes mellitus (E10- } \\
\text { E14) }\end{array}$ & 1172 & 8 & 1380 & 10.2 & $\begin{array}{l}0.76 \\
{[0.7-0.8]}\end{array}$ & $<0.01$ \\
\hline $\begin{array}{l}\text { Renal failure } \\
\quad(\underline{\mathrm{N} 17}-\underline{\mathrm{N} 19})\end{array}$ & 829 & 5.6 & 930 & 6.9 & $\begin{array}{l}0.8 \\
{[0.7-0.9]}\end{array}$ & $<0.01$ \\
\hline $\begin{array}{l}\text { Malignant neoplasms } \\
\text { (드-C97) }\end{array}$ & 1134 & 7.7 & 609 & 4.5 & $\begin{array}{l}1.7 \\
{[1.6-1.9]}\end{array}$ & $<0.01$ \\
\hline $\begin{array}{l}\text { Chronic lower } \\
\text { respiratory } \\
\text { diseases (J40-J47) }\end{array}$ & 1050 & 7.1 & 444 & 3.3 & $2.2[2-2.5]$ & $<0.01$ \\
\hline Heart failure (I50) & 543 & 3.7 & 472 & 3.5 & $1[0.9-1.2]$ & 0.3 \\
\hline
\end{tabular}

OR: Odds Ratio; CI95\%: Confidence Interval 95\%.

by the United Nations, in the World Assembly on Aging in Vienna in 1982. ${ }^{13}$ The increase of this proportion over time as well as the rise of the mean age in our sample, are two points in favor of Ageing of
Tunisian population, which would be achieved when the proportion of elderly accounted at least $15 \%$ of the population. ${ }^{13}$

The slightly predominance of men found in our study has also been noted in Malaysia. ${ }^{14}$ This can be explained by the fact that the health status of Tunisian and Malaysian women remains more conserved than men, since they are less exposed to several risk factors such as tobacco and alcohol use, stress and sexually transmitted diseases. This could be the result of a social, cultural and religious context. Nevertheless, because of the epidemiological and cultural transition that has our country faced since few years, ${ }^{15}$ this situation is going to be reversed in the future and we would probably join the results reported by other studies. In fact, in India ${ }^{16}$ and in Brazil, ${ }^{17}$ a feminine predominance was revealed. The feminization of aged people, a concept which depicts the demographic reality that is almost universally the case that women live longer than men, although in various parts of the world this difference is now decreasing. ${ }^{13}$

Over a whole year, a seasonal variation in hospitalizations was illustrated with a peak in spring. This argues the fragility of this age group due to environmental factors. Indeed, spring in Tunisia is characterized by abrupt changes of the temperature during a whole day.

According to several studies, ${ }^{18,19}$ aged people require an adequate hospital management in case of illness. Furthermore, the mean of LOS is

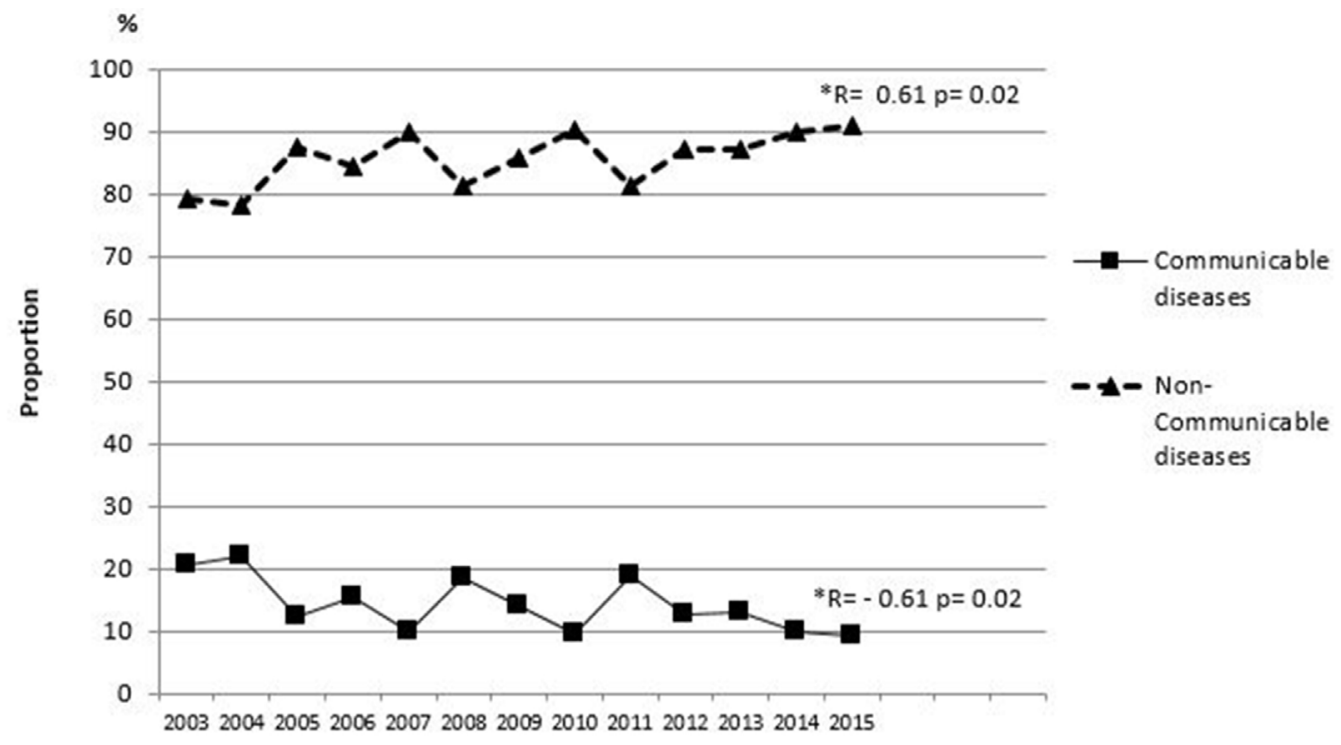

Calendar years

* Rho and p-value using Spearman rank test

Fig. 1. Trends of communicable and non communicable diseases proportions in elderly from 2003 to 2015. 


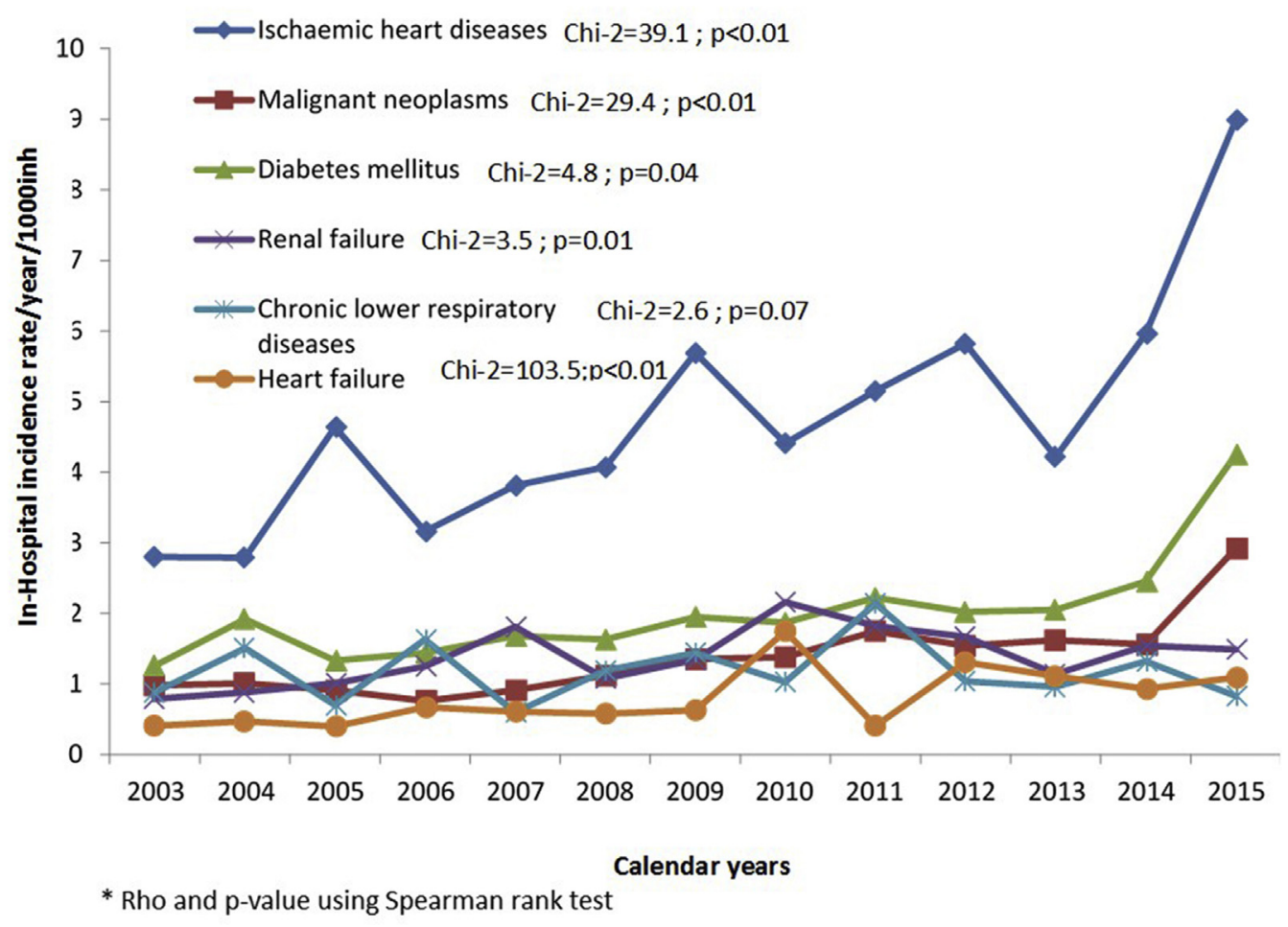

Fig. 2. In-Hospital incidence rates of main diagnoses in elderly per 1000 inhabitants per year from 2003 to 2015 .

generally longer than young people. Similar to other studies, the median LOS was 8 days. A study conducted in Italy revealed an average LOS of 9.4 days. $^{20}$ In Nigeria, according to Onwuchekwa, $33.3 \%$ of patients have been hospitalized less than one week, $56.4 \%$ have been hospitalized between 1 and 2 weeks and 1.5\% have been hospitalized more than one month. ${ }^{21}$ Otherwise, in a Romanian study, a longer LOS was found because of respiratory exacerbation in Chronic Obstructive Pulmonary Disease. ${ }^{22}$ In our survey we noted an elevation of the LOS in some departments such as gastroenterology and pneumo-phtisiology. This can be explained by operational difficulties from which suffer Tertiary-level hospitals in Tunisia, because of the overcharge and the insufficiency of technical platform compared to the needs of population. Therefore, some patients were obliged to be hospitalized for additional days, while waiting for necessary radiological or biological explorations. In Spain, according to Garcia and al. the LOS was 13.3 days, since they have included surgery departments in their survey. ${ }^{11}$ Department of cardiology and pneumo-phtisiology received more than the half of patients, which was concordant with the high prevalence of these pathologies among elderly. According to Garcia, women are often hospitalized in gynecology, rheumatology and endocrinology departments, while men are hospitalized in urology and pneumology departments. $^{11}$

A detailed study of major diagnostic categories of diseases in elderly revealed comparable results with those in the literature. Zedini ${ }^{5}$ and Alballa $^{23}$ noted that cardiovascular diseases as well as digestive system diseases were in the foreground. In the same context, Garcia reported the same results in Spain, ${ }^{11}$ where circulatory system diseases were at the head of the list $(20.7 \%)$, followed by respiratory system diseases (14\%), then digestive system diseases (11.6\%). In Kosovo, cardiovascular diseases represented $63 \%$ of chronic diseases in aged people. ${ }^{24}$

Some studies suggested diseases of the musculoskeletal system, diseases of locomotive system as frequent categories. ${ }^{25,26}$ Compared to our results, these differences could be explained by the fact that our hospital provides only medical care. Furthermore, it doesn't content a department of either neurology or geriatric, which was a study limitation. In Nigeria, according to Onwuchekwa, ${ }^{21}$ infectious diseases occupy the second rank. This could be due to the fact that this country has not yet experienced the epidemiological transition.

Our study showed that renal failure ranked third. This can be explained by the fact that an aged person is more likely to be exposed to risk factors and to worsening conditions such as interstitial nephritis, diabetes mellitus, protein malnutrition, dehydration, cardiac failure, myeloma, nephrotoxic drugs, renal artery stenosis and high blood pressure. ${ }^{16,27}$ Home return was the most common discharge status, and the case-fatality rate was $1.1 \%$ over a 13 -year period. This rate may be underestimated. Indeed, habitually, majority of patients who leave the hospital against a medical advice, are commonly in an altered state. In the Arab-Muslim countries, elderly prefer to die at home rather than at hospitals for cultural reasons. Several studies showed that life expectancy has continuously increased in many countries during the 20th century. At the same time, the number of years spent with chronic diseases seems to be increasing. Literature findings were confirmed in our present study. In fact, there was an emerging and overriding trend of non-communicable disease (NCD) among elderly. Five pathologies which were used as an indicator of chronic diseases evolution (ischemic heart diseases, heart failure, diabetes, malignant neoplasms and renal failure), showed significant increasing trends during the study period. This was probably due to firstly significant socio-economic changes in our society in the last decade, resulting in change of diets, rural-urban drift and changes in lifestyle issues and secondly to the epidemiological transition that our country has experienced in the last decades.

Concerning communicable diseases, we observed a decline in their rate, which was similar to developed countries. However, most of developing countries are nowadays faced to a double burden due to emergence of chronic diseases, added to the persistence of infectious diseases. This decline is related to the effectiveness of different national programs against infectious diseases like vaccine-preventable diseases which has been applied since the 60s.

Buljubašić $M .{ }^{25}$ noted an increasing trend of symptoms, signs and abnormal clinical and laboratory findings, endocrine diseases, and neoplasms. This can be explicated by differences of health systems as well as sociological and epidemiological characteristics between 
countries.

At the end of this survey, we noted that the elderly presented very specific needs linked to multiple diseases and problems that are associated with ageing. ${ }^{28}$ Several studies showed that the hospitalization itself can have ominous effects on the health of elderly and represents a moment of stress that can lead to several complications. ${ }^{29}$ Other works proposed management's alternatives of aged people because of their particularities making them fragile. In the same way, considering the specificity of their pathologies, the prevention must occupy an important place in the management of these aged people: better nutrition, good hydration, vaccination against the flu, adequate physical and social environment as well as an adequate management in case of hospitalization. $^{30}$

In Tunisia, the rapid process of development has brought about demographic and epidemiologic changes. Consequently, the proportion of the elderly has been increasing. The ageing of the population will have far-reaching implications for society. Direct challenges for the health system will include changing health profiles, increased demand for health services use and rising health costs.

Our health system must be prepared to face this situation in the years to come. There is an utmost need for a standardized health policy that makes care of elderly a priority. Quality health services available to them would prevent pain and suffering and would ensure their comfort. This enhances us to create geriatric units, to implement other care pathways for elderly such as home hospital model, to introduce teaching of geriatrics in the basic training of physicians and paramedics and to form geriatricians and gerontologists.

Far from being a negative phenomenon, the increase in the number of hospitalizations in elderly incites health decision makers to review the mode of organization of care services. Adjustments to health care system, particularly hospitals, are therefore needed to answer adequately these needs. It is essential to develop a specific care based on a global geriatric assessment, multidisciplinary care, early intervention, rehabilitation and continuity of care.

\section{Disclosure statement}

The authors declare no conflict of interest.

\section{Ethical approval}

This Research was approved by the committee for the Protection of Persons of Sfax, Medical School of Sfax, Tunisia (Approval File Number 0064/2018).

\section{Appendix A. Supplementary data}

Supplementary data to this article can be found online at https:// doi.org/10.1016/j.cegh.2018.09.002.

\section{References}

1. WHO | The Global strategy and action plan on ageing and health [Internet]. Available from: http://www.who.int/ageing/global-strategy/en/. [Accessed 25 December 2017].

2. Results | Institut National des Statistiques [Internet]. Available from: http://census. ins.tn/en/results-en. [Accessed 25 December 2017].

3. Projection de la population en Tunisie. [Accessed 25 December 2017]. Available from: https://www.google.com/search?q = Projection + de + la + population + en + Tunisie\&ie $=$ utf-8\&oe $=$ utf-8\&client $=$ firefox $-b$.
4. Karampampa K, Drefahl S, Andersson T, Ahlbom A, Modig K. Trends in age at first hospital admission in relation to trends in life expectancy in Swedish men and women above the age of 60. BMJ open. 2013;3(9):e003447.

5. Zedini C, AjmiNabli T, Bougmiza I, et al. The morbidity diagnosed among the elderly in primary care at the sanitary region of Sousse. Tunis Med. févr. 2014;92(2):128-134 2014

6. ICD-10 Version: 2015. Available from: http://apps.who.int/classifications/icd10/ browse/2015/en\#/. [Accessed 25 December 2017].

7. Naik AC, Bhat S, Kholkute SD. Hospitalisation due to infectious and parasitic diseases in district civil hospital, Belgaum, Karnataka. Indian J Publ Health. 2008;52(3):161-163

8. Christensen KLY, Holman RC, Steiner CA, Sejvar JJ, Stoll BJ, Schonberger LB. Infectious disease hospitalizations in the United States. Clin Infect Dis. 2009;49(7):1025-1035

9. Parker MG, Thorslund M. Health trends in the elderly population: getting better and getting worse. Gerontol. 2007;47(2):150-158.

10. Lutomski JE, Baars MA, Boter H, et al. Frailty, disability and multi-morbidity: the relationship with quality of life and healthcare costs in elderly people. Ned Tijdschr Geneeskd. 2013;158 A7297-A7297.

11. García Ortega C, Almenara Barrios J, González Caballero JL, Peralta Sáenz JL. Hospital morbidity of elderly population in Andalusia (Spain). Med Int. 2005;22(1):4-8.

12. Sanya EO, Akande TM, Opadijo G, Olarinoye JK, Bojuwoye BJ. Pattern and outcome of medical admission of elderly patients seen at University of Ilorin Teaching Hospital, Ilorin. Afr J Med Sci. 2008;37(4):375-381

13. Jacob R. Aging and current trends in Malaysia. Aging. 2005; 2035(18):2040. Int J Soc Work Human Serv Pract. 2016;4(3):57-61.

14. Zaki LRM, Hairi NN. Chronic pain and pattern of health care utilization among Malaysian elderly population: national Health and Morbidity Survey III (NHMS III, 2006). Maturitas. 2014;79(4):435-441.

15. Romdhane HB, Khaldi R, Oueslati A, Skhiri H. Transition épidémiologique et transition alimentaire et nutritionnelle en Tunisie. Options Méditerranéennes B. Availablefrom: https://om.ciheam.org/om/pdf/b41/03400042.pdf; 2002, Accessed date: 25 December 2017.

16. Banjare P, Pradhan J. Socio-economic inequalities in the prevalence of multi-morbidity among the rural elderly in Bargarh district of Odisha (India). PLoS One. 2014;9(6):e97832https://doi.org/10.1371/journal.pone.0097832.

17. Macinko J, Camargos V, Firmo JO, Lima-Costa MF. Predictors of 10-year hospital use in a community-dwelling population of Brazilian elderly: the Bambuí cohort study of aging. Cad Saúde Pública. 2011;27:s336-s344.

18. Cei M, Bartolomei C, Mumoli N. In-hospital mortality and morbidity of elderly medical patients can be predicted at admission by the Modified Early Warning Score: a prospective study. Int J Clin Pract. 2009;63(4):591-595.

19. Gray LC, Yeo MA, Duckett SJ. Trends in the use of hospital beds by older people in Australia: 1993-2002. Med J Aust. 2004;181(9):478-481.

20. Liotta G, Mancinelli S, Scarcella P, Gialloreti LE. Determinants of acute hospital care use by elderly patients in Italy from 1996 to 2006. Arch Gerontol Geriatr. 2012;54(3):e364-e369 2012

21. Onwuchekwa AC, Asekomeh EG. Geriatric admissions in a developing country: experience from a tertiary centre in Nigeria. Ethnos. 2008;19(3):359-362.

22. Gyalai-Korpos I, Ancusa O, Dragomir T, Tomescu MC, Marincu I. Factors associated with prolonged hospitalization, readmission, and death in elderly heart failure patients in western Romania. Clin Interv Aging. 2015;10:561. https://doi.org/10.2147/ CIA.S79569.

23. Alballa SR, Bamgboye EA, al-Sekeit M, Alballaa SR. Causes of morbidity among a sample of elderly hospital patients in Riyadh, Saudi Arabia. J Trop Med Hyg. 1993;96(3):157-162.

24. Jerliu N, Toçi E, Burazeri G, Ramadani N, Brand H. Prevalence and socioeconomic correlates of chronic morbidity among elderly people in Kosovo: a population-based survey. BMC Geriatr. 2013;13(1):22. https://doi.org/10.1186/1471-2318-13-22.

25. Buljubašić M, VrcićKeglević M. Morbidity trends of elderly people registered in Croatian family practice: a longitudinal study based on routinely collected data. Coll Antropol. 2014;38(Supplement 2):31-36

26. Motohashi T, Hamada H, Lee J, Sekimoto M, Imanaka Y. Factors associated with prolonged length of hospital stay of elderly patients in acute care hospitals in Japan: a multilevel analysis of patients with femoral neck fracture. Health Pol. 2013;111(1):60-67. https://doi.org/10.1016/j.healthpol.2013.03.014.

27. Sun $Y$, Kassam H, Adeniyi M, et al. Hospital admissions in elderly patients on chronic hemodialysis. Int Urol Nephrol. 2011;43(4):1229-1236.

28. Ruiz M, Bottle A, Long S, Aylin P. Multi-morbidity in hospitalised older patients: who are the complex elderly? Abete P, éditeur. PLoS One. 2015;10(12):e0145372

29. Buurman BM, de Rooij SE. Functional decline in older persons after acute hospitalization. Ned Tijdschr Geneeskd. 2015;159 A8185-A8185.

30. Labella AM, Merel SE, Phelan EA. Ten ways to improve the care of elderly patients in the hospital. J Hosp Med. 2011;6(6):351-357. 